\title{
The Effects of Grain Size Distribution and Structure on Mechanical Behavior of Silty Sand
}

\author{
Shuyun Wang ${ }^{1, *}$, Xiaobing $\mathrm{Lu}^{1}$ and Zhongmin $\mathrm{Shi}^{2}$ \\ 1. Institute of Mechanics, Chinese Academy of Science, Beijing 100190, China \\ 2. China National Offshore Oil Corporation, Beijing 100027, China
}

\begin{abstract}
In order to investigate the effects of the grain size distribution and the micro-structure of soils on the mechanical characteristics, some static triaxial compression tests were carried out, and then the relationship of stress-strain and the strength behavior of silty sand were compared among undisturbed samples with different grain size distribution, undisturbed and remolded samples with the same grain size distribution, and reconstituted samples (or called mixed samples) with different grain size distribution. The effects of grain size distribution and structure on the mechanic behavior of silty sands were mainly analyzed. It is shown that the obvious differences of the mechanical characteristics between undisturbed soils and remolded soils are caused by the differences of soil structures. Although the grain size distribution are different between two soil samples, their mechanical characteristics may be close to each other, or may have obvious differences because of the effects of micro-structure.
\end{abstract}

Keywords: Silty sand, grain size distribution, structure, strength.

\section{INTRODUCTION}

The structural characteristics of soils mean the characteristics of the arrangement of soil, the styles of contact and the pore scales and distribution etc. Generally, the structural characteristics of clay are strong. Therefore, the studies are most on the structural characteristics of clay $[1,2]$. Nevertheless, sand has also structural characteristics [3], especially when sand contains some clay, silt or some organic materials [4]. Up to now, there are few studies are on the structural characteristics of silty sand [5].

In ocean floor, there exists much silty sand which contains some layered or block clay, silt and a few broken shells. Usually, the model tests need a lot of soils, but it is very difficult and expensive to obtain in situ soils [6]. Thus it is practical to use mixed soils to substitute in situ soils. The mixed soils are needed not only have the close physical and mechanical properties with that of situ soils, but also have good quality of repetition.

In the viewpoints above, we find a method to make the mixed soils to replace the in-situ soils, taking the soils in LD site of Bohai Bay, China as an example. First, the physical and mechanical properties of the undisturbed and remolded soils in LD site are experimentally analyzed. Secondly, the mixed soils with different components are made and, the physical and mechanical properties are obtained by triaxial compression tests and grain size distribution tests. Thirdly, the mixed soils whose properties are the most adjacent to that of the undisturbed soils is chosen. In this way, the ratio of components of the mixed soils is determined.

*Address correspondence to this author at the Institute of Mechanics, Chinese Academy of Science, Beijing 100190, China; Tel: 861082544193; E-mail: sywang@imech.ac.cn

\section{EXPERIMENTAL RESULTS AND ANALYSIS}

\section{The Parameters of the Undisturbed Soils}

From three borehole data in Bohai bay LD zone, in 5 20m, the sediment is medium-dense to very dense fine sand containing some broken shell and dispersed clay [7]. Considering the bearing capacity of suction bucket foundations, the soil layer in $0 \sim 20 \mathrm{~m}$ has obvious effects on the bucket. Thus, the main target is to study the properties of soil layer in this range. Therefore, the properties of the sediment among the depth of $5 \sim 20 \mathrm{~m}$ are studied mainly.

In the site LD, the grain series of the fine sand in three boreholes in the depth ranging from 5 to $20 \mathrm{~m}$ are different. The grain size distribution in the range of $12 \sim 15 \mathrm{~m}$ is shown in Fig. 1(a). The basic parameters of four samples are shown in Table 1. The consolidated drained triaxial tests (named CD tests) are carried out under two confining pressures conditions. For comparison conveniently, the stress is expressed by $\left(\sigma_{1}-\sigma_{3}\right) / \sigma_{3}$. The stress-strain curves and volume change strain curves are shown in Fig. (2).

The four samples are all shown brittle failure and obvious dilative behavior. The grain size distribution and the content of clay in each sample are different and so the stress-axial strain curve and the volume change-axial strain are different also. The samples obtained from LD5-2-2 are both dense to very dense fine sand. Thus not only the biggest stresses of these two samples and the effective internal friction are big, but also the stresses increase fast at the first stage and decreases fast also after peak value, which is the obvious brittle behavior.

By comparison of stress - axial strain curves and volume change-axial strain curves of these four samples, it is shown that sample No.1 can reflect the main characteristics of in situ soils. Therefore, the soils for experiments are mainly 


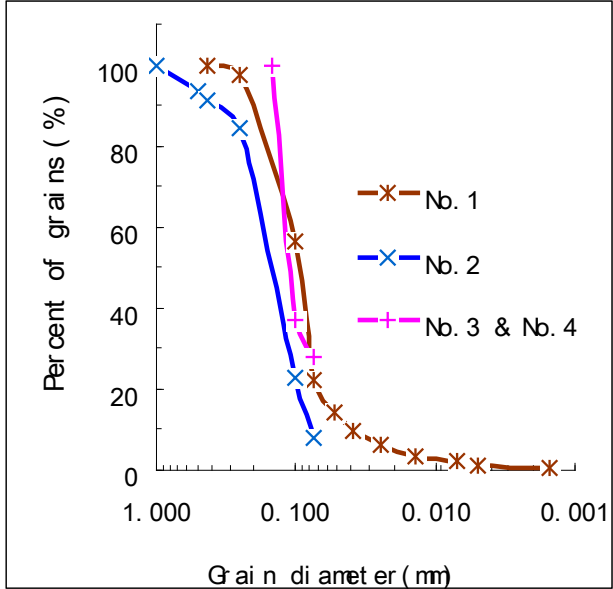

(a) Undisturbed soils

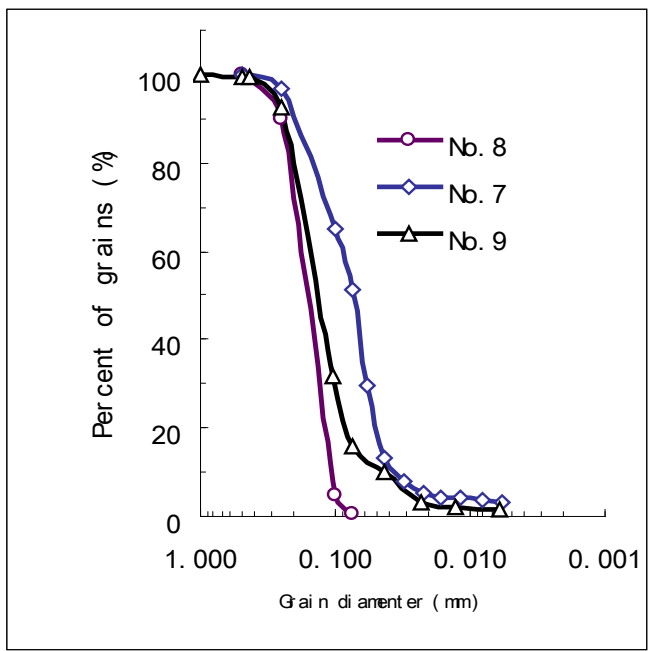

(b) Remolded and mixed soil

Fig. (1). The grain size distribution curves of undisturbed and reconstituted samples.

Table 1. Basic Information About Undisturbed Samples

\begin{tabular}{|c|c|c|c|c|}
\hline $\begin{array}{c}\text { No. of } \\
\text { Samples }\end{array}$ & $\begin{array}{c}\text { Depth/ } \\
\mathbf{m}\end{array}$ & $\begin{array}{c}\text { Density } \\
/ \mathbf{g} / \mathbf{c m}^{\mathbf{3}}\end{array}$ & $\begin{array}{c}\text { Description of } \\
\text { Sample }\end{array}$ & $\begin{array}{c}\text { Confining } \\
\text { Pressure } \\
\mathbf{/ k P a}\end{array}$ \\
\hline \hline No.1 & 12.3 & 2.00 & $\begin{array}{c}\text { Mid-dense silty } \\
\text { sand }\end{array}$ & 100 \\
\hline No.2 & 14.3 & 1.94 & $\begin{array}{c}\text { Mid-dense silty } \\
\text { sand }\end{array}$ & 400 \\
\hline No.3 & 14.2 & 1.98 & $\begin{array}{c}\text { dense silty } \\
\text { sand }\end{array}$ & 100 \\
\hline No.4 & 14.3 & 1.98 & $\begin{array}{c}\text { dense silty } \\
\text { sand }\end{array}$ & 400 \\
\hline
\end{tabular}

made according to the grain size distributions and the mechanical properties.

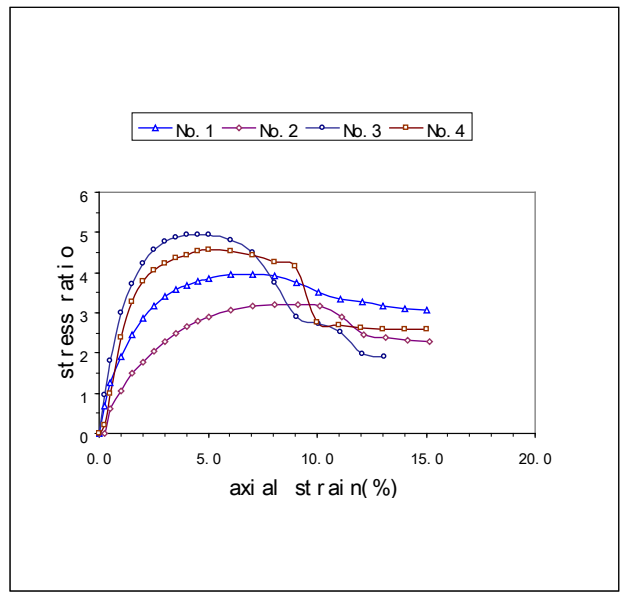

(a) Stress ratio - strain

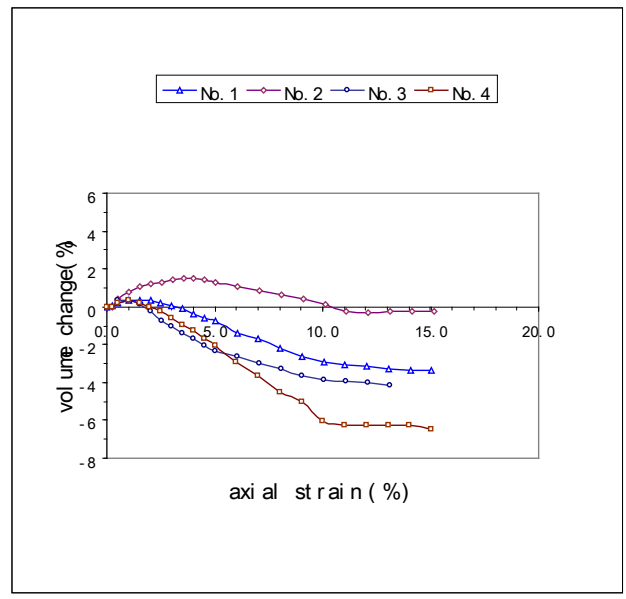

(b) Volume change - strain

Fig. (2). CD test results of undisturbed samples.

It is impractical to made remolded or mixed soils which have most adjacent grain size distributions and the mechanical properties with the undisturbed soils except that the undisturbed soils are not structural. Although the structural characteristics of the undisturbed soils may be simulated partially by lengthening the consolidation time or adding chemical materials into the remolded soils or mixed soils, the experimental cycle is too long. Therefore, it is practical to mix soils having the grain size distributions and mechanical properties as adjacent as possible to that of the undisturbed soils.

For the target, it is needed first to find a kind of fine sand with adjacent grain size distribution and a kind of silty clay containing fine and clay particles. Then mix these two kinds of soils according to different ratio. In this way, we can find an appropriate ratio.

\section{Mechanical Properties of the Remolded and Mixed Soils}

The remolded samples are made by drying, broken and mixing of No.1 with the dry density of $1.6 \mathrm{~g} / \mathrm{cm}^{3}$. So the 
grain size distribution of the remolded soils is the same as that of the undisturbed (Fig. 1(a)).

The grain size distributions of mixed soils are shown in Fig. 1(b). The classification and the basic parameters are shown in Table 2. The sample of mixed soils is saturated with a density of $1.6 \mathrm{~g} / \mathrm{cm}^{3}$ and the confining pressure is 100 $\mathrm{kPa}$.

Fig. (3) is the results of the undisturbed samples (No.1), remolded samples (No.6) and three mixed samples (No.7 No.9). The effects of the grain size distribution and the structural characteristics on the mechanical properties are analyzed according to the curves of grain series, stress axial strain and change $\sim$ axial strain.

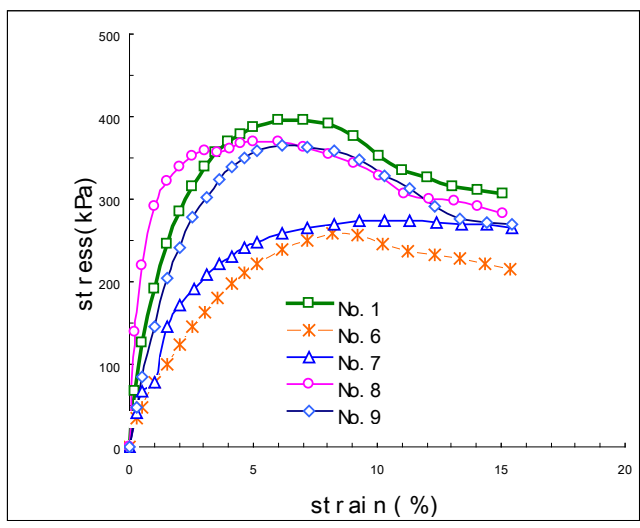

(a) stress $\sim$ axial strain

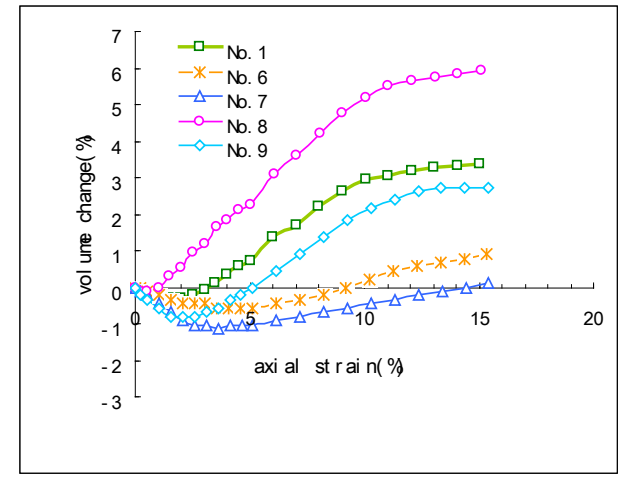

(b) volume change - axial strain

Fig. (3). Comparison of CD results about undisturbed, remolded and mixed samples.

(1) The stress axial strain and the volume change - axial strain relations of the undisturbed samples are obvious different with that of the remolded samples. The strength of the latter is $30 \%$ lower than the former although they both are shown brittle behavior. The undisturbed samples show obvious dilative behavior, while the remolded ones show little dilative behavior. The differences are caused mainly by the structural characters of the soils which are formed by layered silt and clay in the undisturbed soils. The undisturbed samples have experienced the natural course of movement, sediment and consolidation. There are special
Table 2. Basic Information About Remolded and Mixed Samples

\begin{tabular}{|c|c|c|c|}
\hline $\begin{array}{c}\text { No. of } \\
\text { Samples }\end{array}$ & Type of Soil & $\begin{array}{c}\text { Dry Density } \\
\left(\mathrm{g} / \mathrm{cm}^{3}\right)\end{array}$ & Description \\
\hline No.6 & Remolded soil & 1.6 & $\begin{array}{l}\text { Mid-dense silty } \\
\text { sand }\end{array}$ \\
\hline No.7 & Mixed soil & 1.6 & $\begin{array}{l}\text { Mid-dense sandy } \\
\& \text { silty clay }\end{array}$ \\
\hline No.8 & Mixed soil & 1.6 & Dense fine sand \\
\hline No.9 & Mixed soil & 1.6 & $\begin{array}{l}\text { Mid-dense silty } \\
\text { sand }\end{array}$ \\
\hline
\end{tabular}

connections among grains and pore water. The existence and non-uniform distribution of the silty grains and clay grains cause the structural characteristics of the fine sand is higher than the sand but lower than the clay. The structural characteristics lead the undisturbed soils have some structural strength. Although the remolded samples have the same grain series as that of undisturbed, the connections among sand grains, silty grains and clay grains and water is small because of the uniform distribution of grains. In other words, the structural characteristics of the undisturbed samples have been destroyed, which leads to the lower strength.

(2) The three mixed soils have different stress- axial strain relation and volume change $\sim$ axial strain relation. The content of clay in silty clay is high and the strength is the lowest. The samples show plastic failure and no dilatancy. The strengths of fine sand and silty fine sand are approximate equal and the failure mode is brittle. The former has a smaller strain at the peak stress and has a bigger dilatancy. The reason is that there are not silty and clay grain in fine sand, so the diameters are uniform. There occurs obvious dilatancy once the density increases over a critical value during shear.

(3) The mixed silty clay shows plastic failure while the undisturbed soils show brittle failure. The strength of the former is $25 \%$ lower than that of the latter and has no dilatancy. The strength of the mixed fine sand is adjacent with that of undisturbed soils, but the strain at failure is smaller (the former is $5 \%$, the latter is $7 \%$ ) and the dilatancy is bigger.

The strength and the relations of stress-axial strain and the volume change - axial strain of the mixed fine sand is adjacent to that of undisturbed soils. The reason is the effects of grains and grain size distributions are considered in the mixed fine sand. The strength of the fine sand in the mixed fine sand has a high strength while the silty clay has a low strength. The content of fine sand in the mixed sand is $20 \%$ more than that in the undisturbed soils. Therefore, the strength of the mixed fine sand is higher than that of the remolded sand which is caused by the loss of the structural characteristics. 


\section{CONCLUSIONS}

The main conclusions are as follows:

(1) The mechanical properties can be obvious different even if there is a little difference in the grain size distributions of the undisturbed fine sand. The main reason may be the effects of structural characteristics.

(2) The mechanical properties of the remolded and the undisturbed fine sand are different even if the grain size distributions are the same. The main reason is the existence of the structural characteristics of the undisturbed sand while the remolded sand loses its structural character.

(3) The grain size distribution, especially the contents of sand and clay, affects the mechanical properties of mixed sand obviously.

(4) One can find a kind of mixed sand which has the same mechanical properties as that of the undisturbed sand.

\section{REFERENCES}

[1] X.L. Gong, C.X. Xiong and K.X. Xiang, "The formation of clay structure and its influence on mechanical characteristics of clay", Chinese Hydraulic Journal, vol. 22, No. 10, pp. 43-47, 2000.

[2] M.J. Jiang and Z.J. Shen, "Microscopic analysis of shear band in structured clay," Chinese Journal of Geotechnical Engineering, vol. 20, No. 2, pp. 102-108, 1998.

[3] K. L. Lee, "Adhesion bonds in sands at high pressure," Journal of Geotechnical Engineering Division, ASCE, vol. 103, No. GT8, pp. 908-1013, 1997.

[4] R. Dyvik and K. Høeg, "Comparison of tests on undisturbed and reconstituted silt and silty sand," International Workshop on the Physics and Mechanics of Soil Liquefaction, Balkema: Rotterdam, 1999, pp. 159-167.

[5] S. I. Kim, S. S. Jeong, and K. B. Park, "The effects of plastic fines on limited liquefication under monotonic loading," In: Proceeding of 15th International Conference on Soil Mechanics and Geotechnical Engineering, Istanbul, vol. 1, 2001, pp. 163-166.

[6] X.B. Lu, Z.M. Zheng and J.L. Zhang, "Progress in the study on the bucket foundations of offshore platform," Advances in Mechanics, vol. 333. No. 1, pp. 27-40, 2003.

[7] S.Y. Wang, X.B. Lu and Z.M. Shi, "The determination of the static mechanical properties and the parameters of several constitutive relations of the soil in the Luda, Baohai bay, China," Science Report, Institute of Mechanics, Chinese Academy of Sciences, 2003.

Received: July 18, 2009

(C) Wang et al.; Licensee Bentham Open.

This is an open access article licensed under the terms of the Creative Commons Attribution Non-Commercial License (http://creativecommons.org/licenses/by-nc/3.0/) which permits unrestricted, non-commercial use, distribution and reproduction in any medium, provided the work is properly cited. 